\title{
Surgical Management of Schistosoma Refluxes in Cross Bred Holstein Friesian Cow- A Case Study
}

\author{
B. M. Nijin Jos* \\ Veterinary Surgeon, Veterinary Dispensary, Cumbummettu \\ Kerala Animal Husbandry Department, India \\ *Corresponding author
}

A B S T R A C T

Keywords

Bovine, Congenital defect, Schistosoma refluxes and

Cesarean section

Article Info

Accepted:

17 June 2020

Available Online:

10 July 2020
Schistosoma refluxes, a rare and congenital defect seen mostly in ruminants which occurs as result in the failure of closure of the abdominal wall. The defect often leads to abnormal presentation during parturition which in turn leads to dystocia. Mutational operational to correct the abnormal presentation often fail to produce successful results. A cross bred Holstein Friesian cow presented with the symptoms of parturition but unable to deliver the calf was diagnosed as schistosoma refluxes on per vaginal examination. The animal was subject to cesarean section following diagnosis. Following cesarean section it was maintained on antibiotics, fluids and other supportive therapy.

\section{Introduction}

Schistosoma refluxes, a rare and fatal congenital defect which occurs as result of the fissure of the abdominal wall in calves (Laughton et al., 2005). The occurrence of scoliosis leads to abnormal presentation which ultimately leads to dystocia. There are numerous variables that determine whether surgical procedures like cesarean section to be successful. The most important is the health of the dam and calf at the time of surgery. For this reason it is worthwhile to classify cesarean sections as elective, emergency (non-emphysematous) or emphysematous procedures (Newman and Anderson, 2005). A cross bred Holstein Friesian cow presented with the complaint of delayed parturition was diagnosed as a case of dystocia due to schistosoma refluxes and was subjected to cesarean section.

\section{Materials and Methods}

\section{Anamenesis and diagnosis}

A crossbreed Holstein Friesian full term pregnant cow was presented with the 
symptoms of parturition but unable to deliver the calf. Per vaginal examination showed the presence of both hind and for limbs presented together and intestinal loops in the uterine cavity.

\section{Anaesthesia and control}

The surgical procedure was done under xylazine Hydrochloride sedation at the rate of $0.1 \mathrm{mg}$ per kilogram bodyweight and regional anaesthesia was accomplished by inverted $\mathrm{L}$ block using $2 \%$ lignocaine.

\section{Surgical procedure}

The animal was placed in right lateral recumbency and the surgical site was clipped, shaved and prepared for aseptic surgery. An Oblique incision was made in the left lower flank downward and forward. The incision was deepened by incising through the muscle layers and peritoneum to reach the abdominal cavity. The uterus was exteriorized and a knick incision was made in the uterus which was extended with scissors. The foetus was tracted out gently. The uterine opening was closed with catgut 1 in double layer inversion suture pattern, thereafter muscles and skin was apposed in routine manner. Polyglycolic acid 1 was used for apposing muscle layers and Nylon for skin. Post operatively the animal was placed in fluids, antibiotics and other supportive therapy for five days.

\section{Results and Discussion}

A full term pregnant cross bred Holstein Friesian cow presented with the symptoms of parturition was diagnosed as dystocia due to schistosoma refluxes. The animal was subjected to cesarean section. Post operatively animal was maintained on fluids, antibiotics and other supportive therapy. The animal was reported to have recovered uneventfully.

Fig.1 Foetus with Schistosoma Refluxes

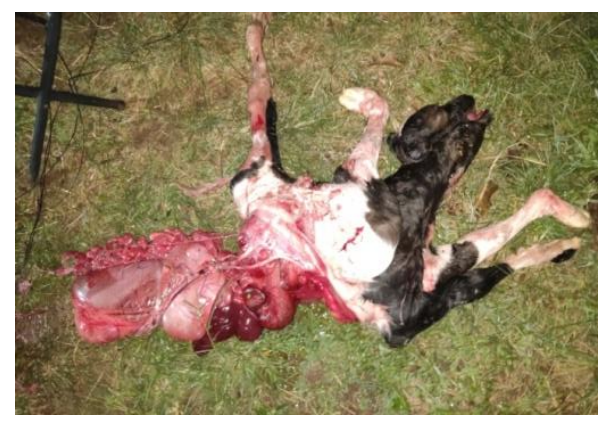

Dystocia defined as delayed or difficult calving, sometimes require significant human assistance. It can occur due to many factors which can be maternal or foetal origin. Schistosoma refluxes a congenital and rare defect that is mostly seen in ruminants. A fatal defect seen following the occurrence of a fissure in the ventral abdominal wall (Laughton et al., 2005). The hypoplasia of the diaphragm was also noticed and so the organs of the thoracic cavity may also be seen along.
The scoliosis that often develops (Laughton et al., 2005) following the occurrence of the defect will lead to the abnormal presentation. As a result of the abnormal presentation it causes dystocia and leads to foetotomy or cesarean section. Cesarean section, one of the most challenging procedures to be done with the goal of preserving dam's and calf's life and future fertility of the cow (Newman and Anderson, 2005). Bovine practitioners are often presented with dystocia that may not be 
able to be corrected by mutational operations proceed to cesarean section (Schultz et al., 2008). There are eight sites which are generally preferred for performing the cesarean section i.e. standing left paralumbar celieotomy, standing right paralumbar celiotomy, recumbent ventral paralumbar celiotomy, recumbent ventral midline celiotomy, recumbent ventral paramedian celiotomy, ventrolateral celiotomy and standing left oblique celiotomy (Schultz et al., 2008). The most common indications that require cesarean section to be performed are immature heifers, pelvis deformities, failure of cervical dilation, uncorrectable uterine torsion, uterine tear, hydrops, prepartum paralysis, absolute oversized fetus, malposition and pathological foetal conditions (Campbell and Fubini, 1990). Although many sites are cited for performing cesarean section left oblique ventrolateral site is the most commonly adopted site as their occurs minimum post operative contaminations and lesser post operative complications (Verma et al., 1974 and Singh et al., 1978).

\section{Acknowledgement}

The author would like to acknowledge Director, Kerala Animal husbandry
Department and District Animal Husbandry Officer, Idukki for providing the facilities for the successful completion of the work.

\section{References}

Campbell, M.E. and Fubini, S.L. 1990. Indications and surgical approaches for cesarean section in cattle. Compend. Contin. Educ. Pract. Vet. 12:285-292.

Laughton, K. W., Fisher, K. R. S., Halina, W. G. and Partlow, G. D. 2005. Schistosomus Reflexus Syndrome: A Heritable Defect in Ruminants. Anat. Histol. Embryol. 34(5):312-318.

Newman, K.D. and Anderson, D.E. 2005. Cesarean section in cows. Vet Clinics Food Anim. 21:73-100.

Schultz, L. G., Tyler, J. W., Moll, D. H. and Constantinescu, G.M. 2008. Surgical approaches for cesarean section in cattle. Can. Vet. J. 49(6): 565-568.

Singh, J., Prasad, B. and Rathor, S.S. 1978. Torsio uteri in buffaloes (Bubalus bubalis)- An analysis of 65 cases. Indian Vet. J. 55:161-165.

Verma, S.K., Manohar, M. and Tyagi, R.P.S 1974. Cesarean section in bovines: A clinical study. Indian Vet. J. 51:471479.

\section{How to cite this article:}

Nijin Jos, B. M. 2020. Surgical Management of Schistosoma Refluxes in Cross Bred Holstein Friesian Cow- A Case Study. Int.J.Curr.Microbiol.App.Sci. 9(07): 2066-2068. doi: https://doi.org/10.20546/ijcmas.2020.907.238 